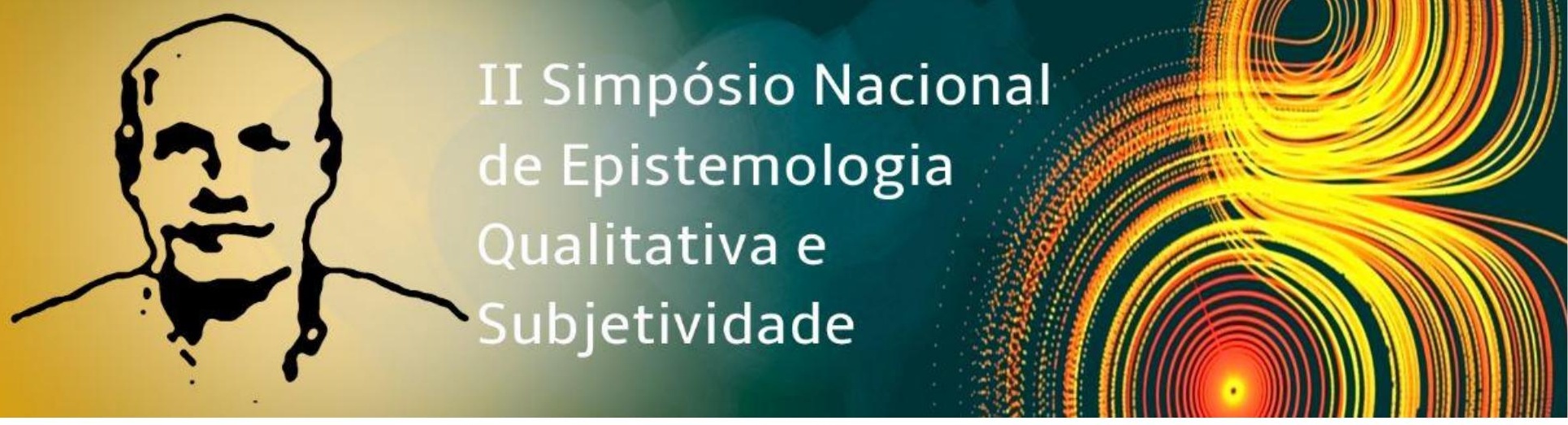

Eixo temático: A utilização da epistemologia qualitativa e a metodologia construtivo-interpretativa na pesquisa e na prática profissional;

\title{
DE ESPAÇO FÍSICO A LUGAR: EM BUSCA DA VALORIZAÇÃO DOS SENTIDOS SUBJETIVOS DAS CRIANÇAS DA EDUCAÇÃO INFANTIL
}

Aline Constância de Figueiredo e Souza Universidade Federal do Rio Grande do Norte aline.cfs@hotmail.com

\section{Resumo}

Este trabalho é um recorte de uma pesquisa de mestrado na área da educação que objetiva analisar as configurações e a organização dos espaços numa instituição de Educação Infantil, e a forma como as crianças se relacionam com/nesse espaço, na busca em compreender como elas percebem esses espaços e os sentidos subjetivos que dão para esse lugar. Trata-se de uma pesquisa que tem uma abordagem de investigação qualitativa, a partir dos estudos etnográficos, onde se propõe uma aproximação com a teoria da subjetividade (GONZALEZ REY, 2012, 2001, GONZÁLEZ REY, MITJANS MARTINEZ E BEZERRA (2016), GONZALES REY, TACCA, 2008) e com a metodologia construtivo-interpretativa (ROSSATO e MITJANS MARTÍNEZ, 2018) que mostram-se como um suporte teórico-metodológico significativo nos caminhos dessa pesquisa. No fazer da pesquisa, ressaltamos a importância de olharmos às crianças como sujeitos completos, sociais, culturais e repletos de historicidade, que adentram os espaços educativos e no seu fazer/viver diário, significam esses espaços. Dessa forma, defendemos que os significados e sentidos subjetivos emprestados/construídos pelas crianças, são valiosos na constituição de espaços educativos que as considerem, valorizem, se importem com seus interesses e necessidades. Assim, partimos do entendimento da grande importância que a qualidade das vivências estabelecidas nos espaços das instituições de Educação Infantil representam para as crianças e suas infâncias e que os espaços escolares não estão/são prontos, são construídos e modificados coletivamente no dia a dia da escola. Dessa forma, a partir dos autores como Forneiro (1998), Horn (2004), Viñao (2005), Oliveira (2007), nos aproximamos de uma visão do espaço como algo dinâmico, que atende às necessidades das pessoas que nele convivem, influenciando seus comportamentos, apontando para a importância de pesquisar e refletir sobre a (re)organização dos espaços físicos, a partir dos significados das crianças, na constituição das relações entre os sujeitos que participam do cotidiano da Educação Infantil.

Palavras chave: Educação Infantil; Espaços Físicos; Significados. 


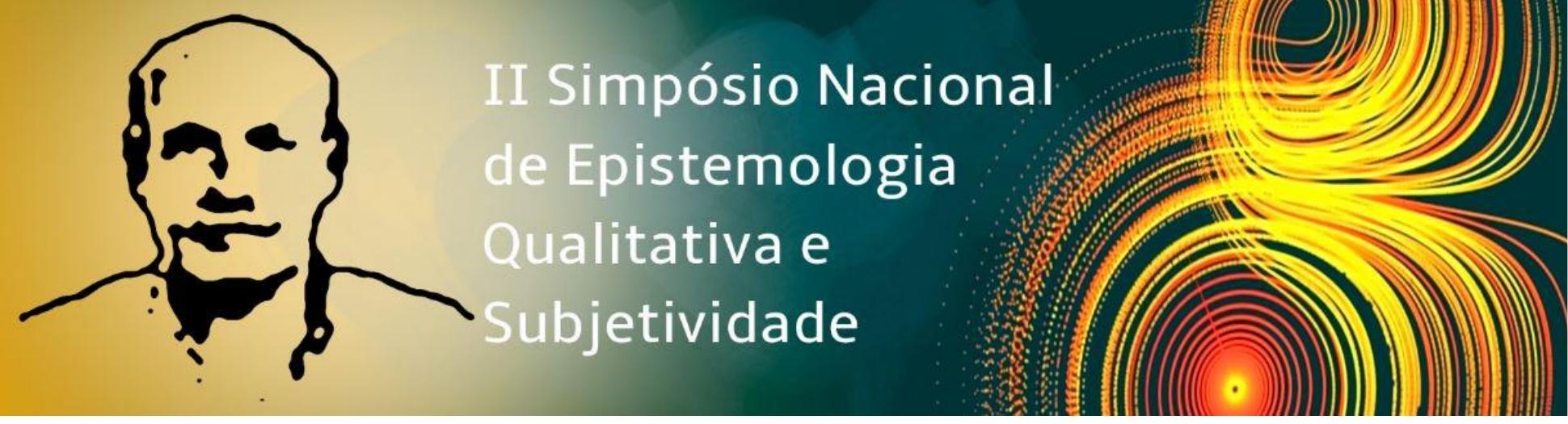

\section{1- Introdução}

Este trabalho é um recorte de uma pesquisa de mestrado na área da educação, que objetiva analisar as configurações e a organização dos espaços numa instituição de Educação Infantil, e a forma como as crianças se relacionam com/nesse espaço, na busca em compreender como percebem esses espaços e os sentidos subjetivos que dão para esse lugar.

Trata-se de uma pesquisa qualitativa, a partir dos estudos etnográficos, onde se propõe uma aproximação com a teoria da subjetividade como um suporte teórico-metodológico significativo nos caminhos da pesquisa em questão.

Partimos do entendimento que as crianças são seres sociais, capazes de elaborar e ressignificar a realidade na qual estão inseridas. Nesse sentido, propomos uma aproximação com as crianças de um Centro Municipal de Educação Infantil da cidade de Salvador/BA, buscando compreender melhor o seu cotidiano, suas interações, experiências e brincadeiras no espaço da instituição.

A opção pela pesquisa etnográfica e pelos estudos da teoria da subjetividade, se deu pelo fato de permitir uma maior aproximação com as culturas infantis, possibilitando uma descrição detalhada dos modos pelos quais ocorrem as interações e relações entre elas (SIMÃO, 2014). Essas abordagens possibilitaram uma melhor percepção de como os diversos espaços da instituição são utilizados, como as interações das crianças entre elas, nos e com os espaços, são realizadas e identificar como percebem e significam esses lugares. Para tanto, vale destacar, conforme Simão (2014), que nesse tipo de pesquisa é necessário um grande empenho na busca por nos tornarmos capazes de ouvir, interpretar e valorizar os pontos de vista das crianças como contribuição.

Ressaltamos que esse estudo objetiva realizar uma pesquisa com as crianças, pois "[...] pouco se conhece sobre as culturas infantis porque pouco se ouve e pouco se pergunta às crianças e, ainda assim, quando isso acontece, a 'fala' apresenta-se solta no texto, intacta, à margem das interpretações e análises" (QUINTEIRO, apud DELGADO E MÜLLER, 2008, p. 162).

Nesse sentido, Cruz (2009) aponta que a grande maioria das pesquisas na área da Educação Infantil privilegia a perspectiva do adulto sobre a da criança, apontando que se fala 


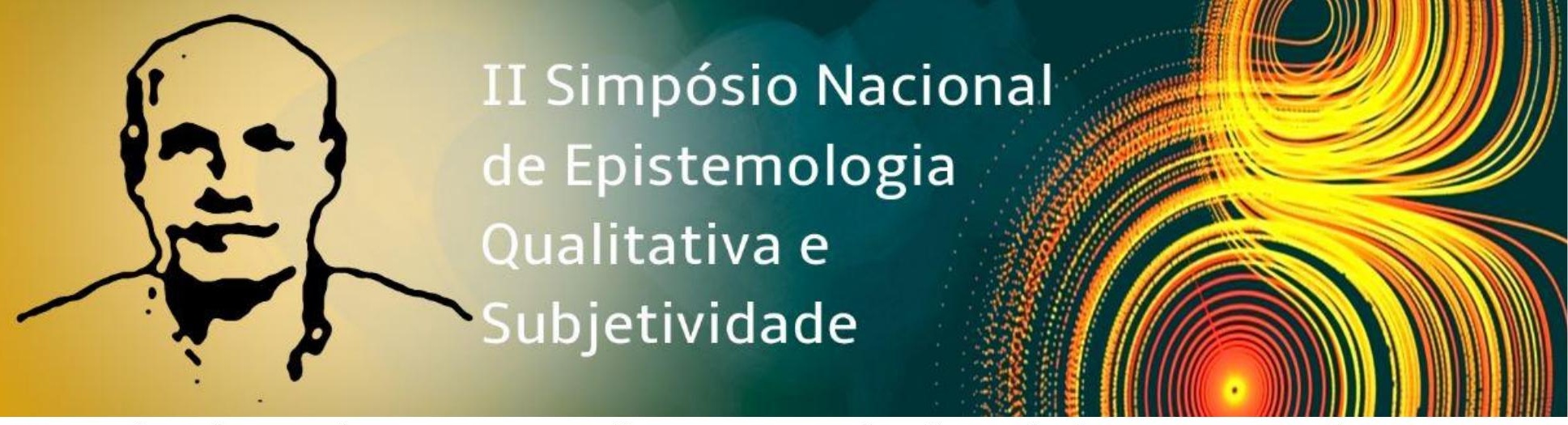

muito sobre as crianças, mas pouco diretamente com elas. Concordando com essa questão, Oliveira-Formosinho, Khishimoto e Pinazza (2007) ressaltam a importância das crianças serem vistas, ouvidas e escutadas durante as investigações, colocando as expectativas e opiniões infantis no centro das atenções.

Como colaboração na busca pelos sentidos subjetivos das crianças em relação aos espaços físicos que frequentam na instituição de Educação Infantil, levando em conta as dificuldades inerentes as pesquisas com crianças pequenas, que ainda são minoria, nos aproximamos da metodologia construtivo-interpretativa (ROSSATO e MARTÍNEZ, 2018), que mostrou-se como importante aporte teórico-metodológico.

Estudos do aporte teórico da Sociologia da Infância, nos levam a pensar sobre as crianças pequenas enquanto protagonistas ativas das práticas sociais, que interpretam e ressignificam a cultura na relação com seus pares, que são capazes de construir modos de significação do mundo e de ação intencional, que são distintos dos modos adultos (SARMENTO, 2003). Dessa forma, também no dia a dia da Educação Infantil, as crianças interagem com/nos diversos espaços, a partir das possibilidades que lhe são oferecidas e assim, numa trama individual e coletiva, onde as ações, emoções, afetividades e expectativas, vão dando sentidos para esses espaços. Nessa tentativa de perceber esses sentidos, que são subjetivos, nos remetemos a González Rey, Mitjans Martinez e Bezerra (2016), quando nos dizem que a subjetividade é produzida dentro de elos de onde emergem os sujeitos sociais e individuais.

O que se busca com essa pesquisa não é a precisão do conhecimento, mas a profundidade da participação ativa dos investigados, assim, a participação das crianças foi extremamente rica, pois, por meio das suas falas, interações, dos seus gestos e expressões, percebidos no decorrer da pesquisa, pudemos analisar os sentidos subjetivos e os significados que atribuem aos espaços escolares e discutir os caminhos e principais resultados da pesquisa.

Dessa forma, focamos nosso olhar investigativo na instituição de Educação Infantil como um espaço eminentemente social e cultural, um direito da criança, que tem por finalidade cuidar e educar, onde a partir das práticas pedagógicas vividas se torna um lugar da criança viver sua infância, sendo respeitada em suas especificidades. 


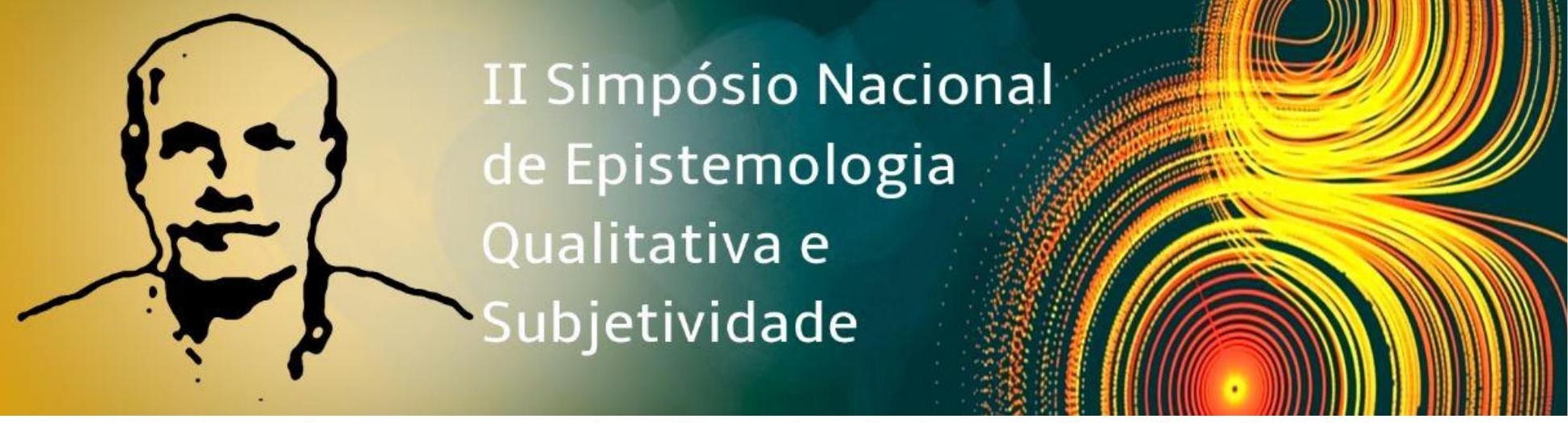

Apesar de constatarmos que, áreas diversas do conhecimento realizam discussões sobre o espaço físico das instituições de Educação Infantil, poucas pesquisas pretenderam analisar esse espaço através do ponto de vista das crianças, percebendo os significados que as crianças emprestam como caminhos para a construção de lugares em que possam viver plenamente as suas infâncias.

\section{2- Educação Infantil: espaços que se transformas em lugares}

No Brasil, desde a Constituição de 1988 (BRASIL, 1988), a Educação Infantil é considerada um direito da criança e dever do Estado. Com base em diversos estudos e debates, vários documentos legais foram sendo construídos no Brasil, buscando garantir um atendimento de qualidade que respeitasse as crianças pequenas em suas especificidades.

Porém, ainda nos deparamos com uma realidade preocupante em relação a qualidade das instituições de Educação Infantil no Brasil. Nesse sentido, Horn (2004, p.14) alerta que “[...] um dos aspectos mais evidentes dessa difícil situação diz respeito à organização dos espaços nas instituições de educação infantil, sugerindo daí a relevância dessa temática".

Tentando nos aproximar de uma visão do espaço como algo dinâmico, que atende às necessidades das pessoas que nele convivem, influenciando seus comportamentos, é que Forneiro (1998) relata que estamos acostumados a pensar o espaço como algo estático, mas que no entanto, "[...] é necessário entender o espaço como um espaço de vida, no qual a vida acontece e se desenvolve: é um conjunto completo" (BATTINI apud FORNEIRO, 1998, p.231).

Assim posto, é importante compreendermos os termos espaço e lugar, que são utilizados muitas vezes como sinônimos, mas que guardam significativas diferenças. Portanto, perguntamo-nos: O que é o espaço? O que é o lugar?. Forneiro (1998, p.232) argumenta que o termo espaço se refere "[...] aos locais para a atividade caracterizados pelos objetos, pelos materiais didáticos, pelo mobiliário e pela decoração". Porém, a forma que esses espaços e materiais são utilizados e as relações pessoais que se estabelecem nele, elevam-no a um novo patamar, quando então passamos a chamá-lo de lugar (FORNEIRO, 1998). 


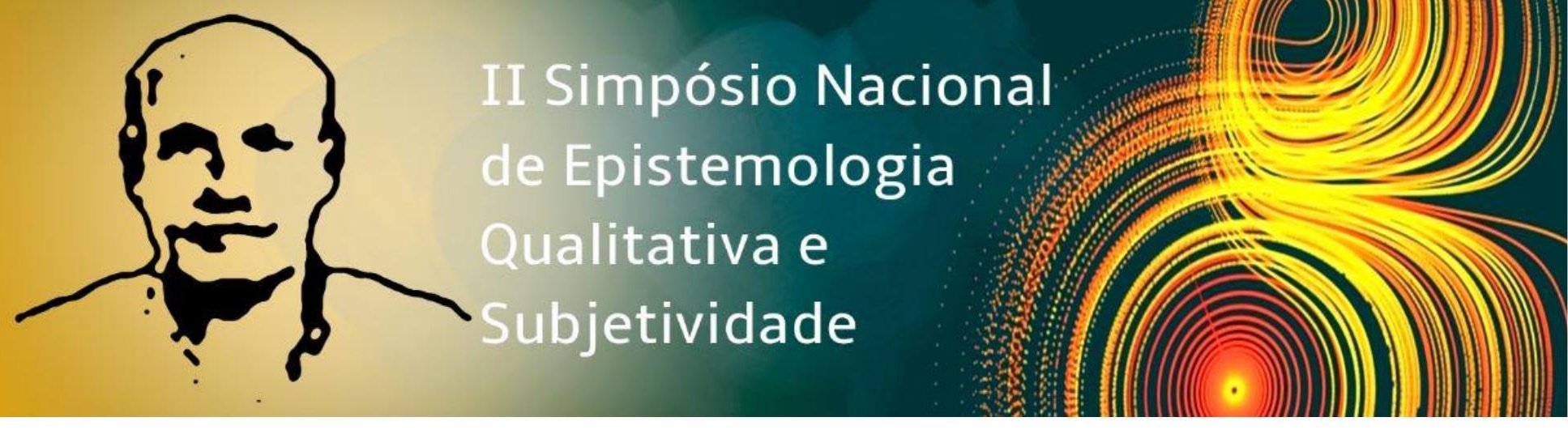

3- O contato com o dia a dia das crianças e seus sentidos subjetivos sobre os espaços da Educação Infantil: primeiras considerações.

Nos primeiros contatos com a instituição, fomos imersas em um mix de sentimentos. Por um lado, total indignação por perceber uma estrutura física totalmente inadequada para o atendimento às crianças. Por outro, o encantamento de ver como as paredes, tetos, sorrisos e afagos mostravam que aquele lugar valorizava as crianças e do esforço de transformar aquele espaço, num lugar de infâncias.

A instituição atende 128 crianças de dois a seis anos, em tempo integral, funciona num prédio alugado pela prefeitura há seis anos, onde das oito salas disponíveis, sete não possuem janelas, portanto não tem nem iluminação e nem ventilação natural. Algumas salas são extremamente pequenas.

O teto das salas é feito de uma madeira compensada, de péssima qualidade, onde os ruídos das pessoas que transitam, incomodam e até assustam as crianças. Ressaltamos que em algumas salas, esse teto tem pontos de mofo, o que, junto com a falta de ventilação e iluminação natural, colabora para que muitas crianças e também professoras, tenham constantemente problemas respiratórios. Além dessas questões, muitas outras inadequações envolvendo o espaço físico são observadas na instituição, fugindo das diretrizes indicadas nos documentos oficiais brasileiros.

Apesar das dificuldades, percebemos que existe um esforço grande por parte da equipe, seja direção, coordenação e professores, em qualificar esse lugar. Em diversos espaços, como corredores, tetos, salas e hall de entrada, vimos produções das crianças expostas, que, além de decorarem os espaços, convidam crianças e adultos a apreciarem as produções e descobrirem o que as crianças dos diversos grupos têm feito na escola. Pudemos ver expostos, desenhos, pinturas, colagens, modelagens, fotos, textos, pesquisas etc. Uma variedade de trabalhos que encanta os visitantes e enche as crianças de orgulho, pela valorização e pelo entusiasmo em mostrar suas produções para os pais, colegas e funcionários da escola e assim, esse espaço vai nos contando que esse lugar é vivo e dinâmico, que lá os saberes das crianças são respeitados, que lá as crianças ampliam seu conhecimentos de mundo, que brincam. 


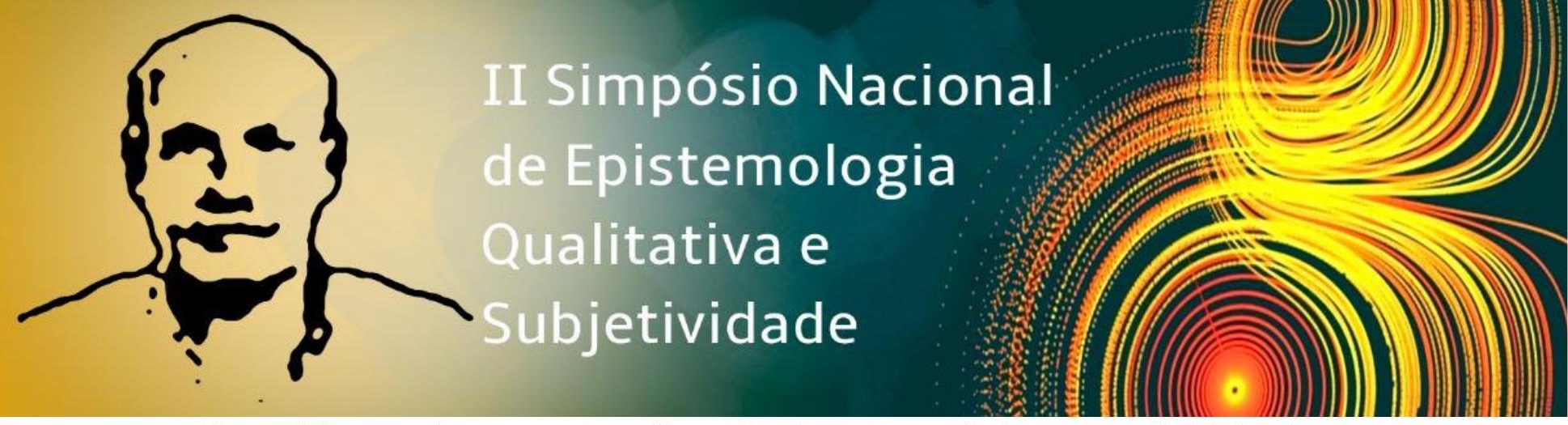

Mas também, percebemos que as configurações desse espaço, limitam as possibilidades de uso, de experiencias, o conforto, a segurança e bem estar de todos que a ele frequentam. Pensamos, o quanto espaços adequados acrescentariam ricas possibilidades de vivencias, colaborando para entender, sua influência na dinâmica da instituição e consequentemente no desenvolvimento e dignidade das crianças.

Em diversos momentos, vimos que as crianças têm suas ideias e opiniões valorizadas, quando são ouvidas, respeitadas e colocadas como participantes ativos da dinâmica pedagógica. São vistas como competentes, capazes de serem influenciadas pelo meio, mas também influencia-lo, explorando e modificando os espaços utilizados, transformando-os no dia a dia e lhes caracterizando em espaços próprios, espaços marcados por elas, tornando-se em lugares cheios de significados e sentidos subjetivos.

Dessa forma, corroboramos com a teoria da subjetividade, quando entendemos que todo processo educativo que tem como objetivo a emergência/valorização dos sujeitos, só se faz com processos participativos, onde os indivíduos sintam que tem um espaço social, que fazem parte de um todo e são respeitados e apreciados pelos demais sujeitos que dele fazem parte (GONZÁLEZ RAY, MITJANS MARTINÉS, BEZERRA, 2016).

Buscamos na convivência diária com as crianças, os caminhos para a realização da pesquisa, onde a Metodologia Construtivo-Interpretativa colaborou na reflexão desses caminhos ainda pouco explorados nas pesquisas com as crianças pequenas. Assim, torna-se importante trazer à tona como forma de somar as discussões de pesquisas que pretendem ter a participação direta das crianças pequenas da Educação Infantil.

Inicialmente, percebíamos que tínhamos que fazer parte do dia a dia daquele lugar, nos aproximando das crianças, criando laços de confiança e afetividade. Assim, passamos dois meses estando quase que diariamente na instituição, juntos das crianças, deixando de ser estranhos também, para os professores, que foram demonstrando estarem mais a vontade com a nossa presença. Vale destacar que o processo todo da pesquisa foi gerador de conhecimentos na busca dos sentidos subjetivos das crianças.

Nesse percurso, as lentes teóricas aguçavam o olhar e muitas questões observados em relação a rotina e utilização dos espaços foram iluminadas, ora trazidas pelas próprias crianças, ora percebidas pela pesquisadora e questionadas as próprias crianças. 


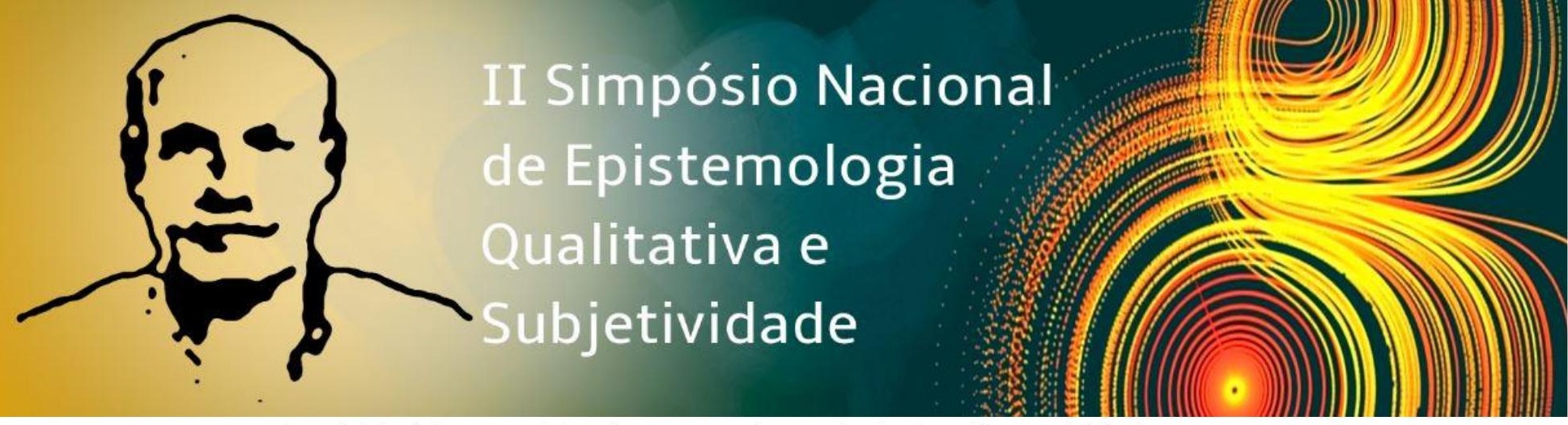

seu contexto cultural, histórico e social e alerta para a importância daquilo que é falado no momento das produções dos desenhos o que colaborará para apreensão da fala infantil.

Vale destacar, que os desenhos na metodologia construtiva-interpretativa são tomados como colaboradores da expressão do outro, sendo um meio para a produção de informações e não são tidos como categorias em si mesmo. Assim, as observações, os momentos informais e as entrevistas atreladas aos desenhos foram fundamentais no percurso da pesquisa para a percepção dos sentidos subjetivos das crianças em relação aos espaços físicos da instituição. Como destaca Rossato e Martínez (2018, p. 188), "A interlocução entre os instrumentos gera uma singularidade de informações que foge às regras padronizadas de produção de conhecimento, uma vez que requerem a participação interpretativa e construtiva do pesquisador ao longo de toda a pesquisa".

Assim, estar no dia a dia da instituição, nos aproximando das crianças e professores, nos possibilitou compreender o quanto as crianças percebem que esse espaço é pensado para elas e nos digam com muita alegria que adoram estar lá todos os dias, brincando, aprendendo, estando junto das demais crianças e adultos, explorando, inventando. Dessa forma, a partir da percepção dos significados gerados pelos sentidos subjetivos, demostraram que para elas os espaços da instituição se transformas em lugar de brincar, lugar de estar junto e lugar de explorar. Podemos perceber esses aspectos em falas como, “Adoro brincar com meus amigos e com a minha professora!"; “Gosto muito de estudar, aqui a gente aprende coisas legais”; “Gosto muito do parque porque lá dá para correr, brincar de esconde-esconde, pega-pega”; “O corredor é lindo com as nossas tarefas!”; "Gosto da escola porque a gente pode ler, escrever, pintar, fazer aventura e brincar!".

Porém, falas como, "Não gosto quando chove, o parque fica escorregadio, ai a gente não vai"; "A água do banheiro é fria e eu queria que ele fosse mais bonito, podia ter uma plantinha, uma flor roxa!”; "Eu queria muito uma janela na sala! Eu amo janela!"; “A gente faz xixi no vaso do banheiro da cozinha, mas ele tá entupido. Não pode acontecer isso!'”; “Gosto mais ou menos do parque porque tem pouco brinquedo, podia ter escorregador!”, "Na sala o ar quebrou e a gente fica com muito, muito calor!”; "O teto faz zuada. Pode ser um lobo, mas não é”, apontam que as crianças também têm muita propriedade para apontar o que as deixa insatisfeitas e dizem muito além do que os adultos muitas vezes acreditam que elas tenham entendimento. Assim, nos dizem que os espaços e equipamentos inadequados ao uso, 


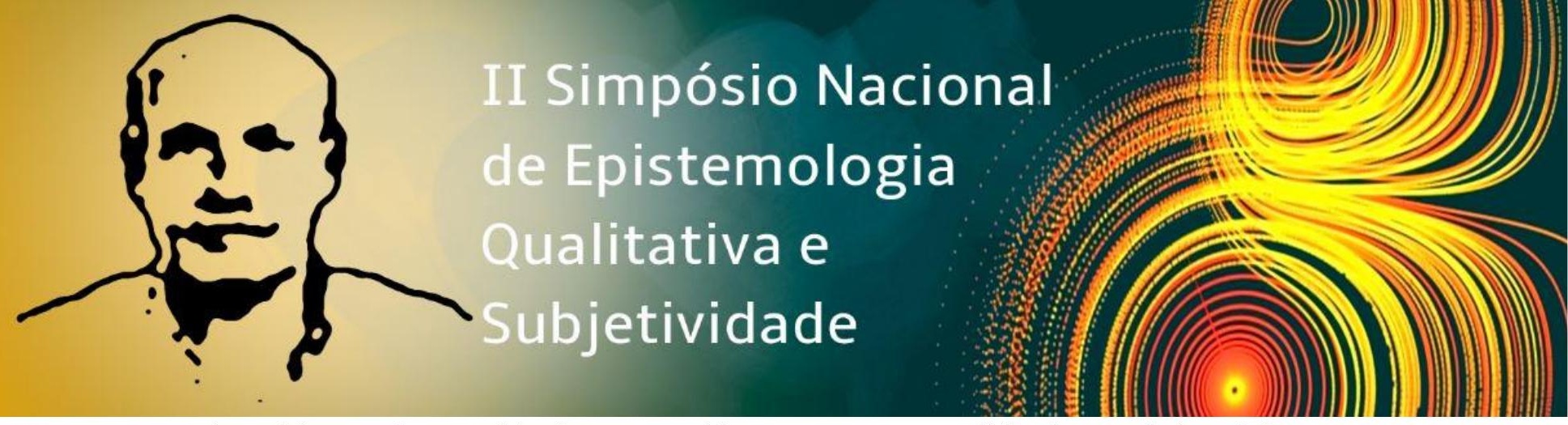

espaços inestéticos e desagradáveis aos sentidos e espaços que dificultam a brincadeira e os movimentos, geram insatisfação, e são por elas percebidos e significados.

Assim no dia a dia da pesquisa e nos diálogos constantes com as crianças, elas nos contaram que os constantes defeitos nos aparelhos de ar condicionado e ventiladores as incomodavam principalmente ao voltarem suadas do parque e nos momentos de dormir; nos falaram sobre como um dos sanitários quebrados dificultava o uso do banheiro; disseram que queriam um melhor cuidado com a limpeza dos banheiros e a vontade desses serem mais esteticamente agradáveis; que queriam mais privacidade no momento do banho; que gostariam de uma janela na sala; disseram que desejam brincar mais tempo no espaço externo; contaram que desejam ter um espaço próprio para fazer as refeições e para que as crianças que não quisessem dormir pudessem ficar; nos contaram de como se chateavam quando o ar condicionado com defeito jogava agua nos seus trabalhos; de como o espaço ficava apertado nos momentos de dormir; falaram que desejam mais brinquedos nos parques, dentre tantas outras questões.

Para isso ressaltamos que os diálogos com as crianças,

[...] aparecem como momento essencial da pesquisa. Os processos subjetivos complexos só aprecem na medida em que os sujeitos estudados se expressam através de sua implicação pessoal, aparecendo na pesquisa através de suas próprias construções que avançam e se enriquecem no diálogo permanente com o pesquisador e no próprio diálogo dos sujeitos pesquisados entre si (GONZALEZ REY, 2001, p.12).

Percebíamos assim, nos mais simples gestos e nas atitudes mais expressivas das crianças, como os espaços iam sendo significados. A partir das mais variadas interações [entre crianças, adultos, ambiente e materiais], eram impressas marcas próprias nesses espaços, marcados pelos sentimentos, pelas emoções, pelos fazeres, pelos movimentos, pelas curiosidades, pelas amizades, pelas descobertas e pelos desafios que lhe permeiam, destacando que "Toda ação e relação que gere emocionalidade é produtora de sentidos subjetivos (ROSSATO E MARÍNEZ, 2018, p. 192)”.

Nesse percurso diário fomos construindo os resultados da pesquisa, destacando que, na busca dos sentidos subjetivos, 


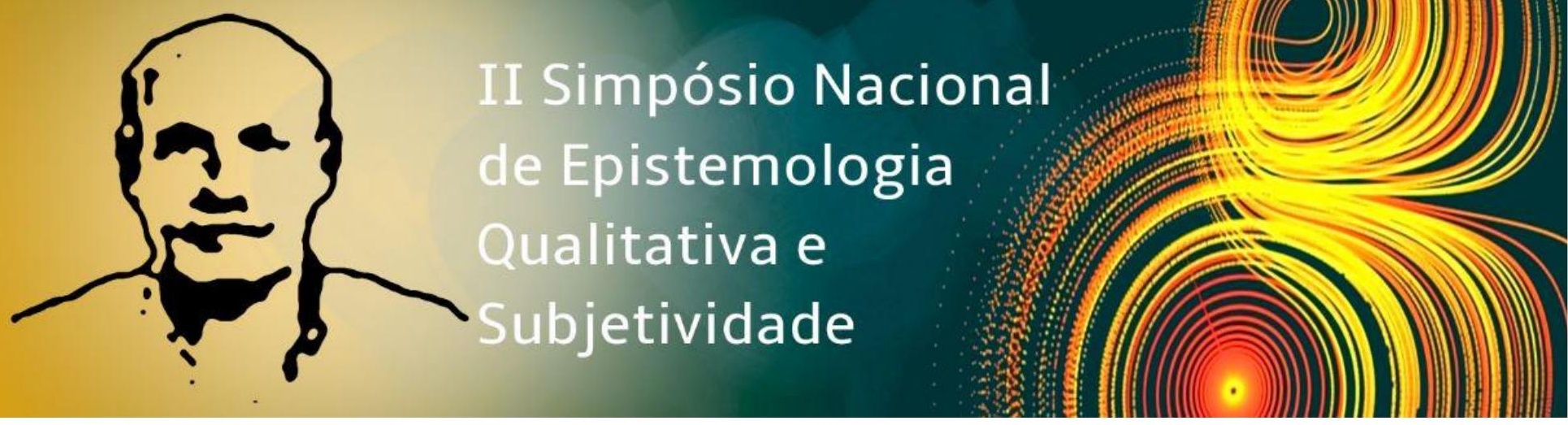

A interpretação e a construção do pesquisador requerem um olhar sensível, capaz de movimentar a tessitura das informações desde as mais particulares até as mais gerais sem, contudo, ficar preso aos fatos narrados e descritos pelos participantes, mas aproximando-se dos processos e formações subjetivos produzidos nas vivências dos mesmos, sempre fruto da interpretação qualificada e fundamentada pela base teórica do pesquisador (ROSSATO E MARÍNEZ, 2018, p. 191).

Finalizamos ressaltando mais uma vez os desafios de realização pesquisas com a participação direta das crianças pequenas e da importância de olharmos as crianças como sujeitos completos, sociais, culturais e repletos de historicidade, que adentram os espaços educativos e no seu fazer/viver diário, significam esses espaços.

Dessa forma, defendemos que os significados e sentidos subjetivos emprestados/construídos pelas crianças, são valiosos na construção de espaços educativos que as considerem, as valorizem, se importem com seus interesses e necessidades. Assim, pensamos que vale a pena refletir sobre a seguinte questão: como adequar ou desenvolver metodologias de pesquisas que possam captar os sentidos subjetivos de crianças tão pequenas como as da Educação Infantil?

\section{Referências}

BenCOSTTTA, M. L. A. Arquitetura e espaço escolar: o exemplo dos primeiros grupos escolares de Curitiba (1903-1928). In: BENCOSTTA, M. L. A. (Org.). História da Educação, Arquitetura e Espaço Escolar. São Paulo: Cortez, 2005.

BRASIL. Referencial Curricular Nacional para a Educação Infantil. Brasília: MEC/SEF, 1998.

Constituição da República Federativa do Brasil. Brasília: Centro Gráfico do Senado, 1988.

BUCCI, Lorenzza. Os desafios da pesquisa com crianças: Diálogos entre teoria e prática. In: 37ª Reunião Nacional da ANPED. Florianópolis, SC, 2015.

CRUZ, R. C. A. (2009). A pré-escola vista pelas crianças. In: 32 Reunião da ANPED. Caxambú, MG, 2009. 


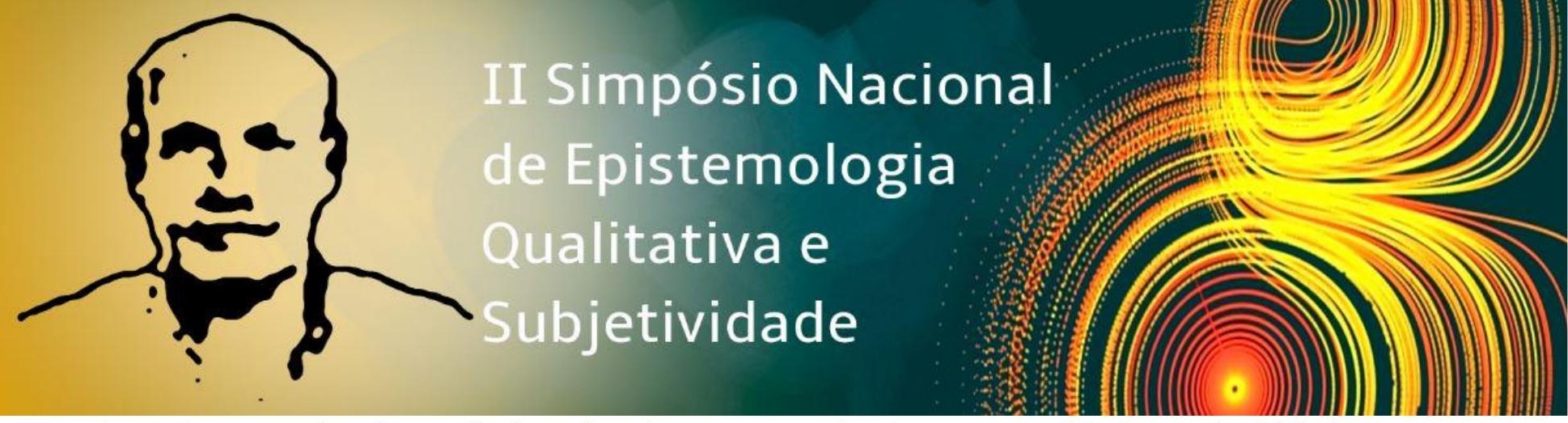

Aprender: exercitando os direitos da criança na escola. Araraquara, SP: Junqueira\&Marin; Brasília, 2007.

SARMENTO, Manuel Jacinto. As Culturas da Infância nas Encruzilhadas da Segunda Modernidade, In M.J. Sarmento e A.B. Cerisara (org), Crianças e miúdos. Perspectivas SócioPedagógicas da Infância e Educação. Porto. Asa, 2003.

SIMÃO, M. B. Pesquisa etnográfica com crianças pequenas: reflexões sobre o papel do pesquisador. Ver, Diálogo Educ., Curitiba, v.14, n. 41, p. 37-59, jan./abr. 2014.

SOUZA, Solange Jobim e; CASTRO, Lucia Rabello de. Pesquisando com crianças: subjetividades infantil, dialogismo e gênero discursivo. In Cruz, S. H. V. (org), A criança fala: a escuta de crianças em pesquisas. São Paulo: Cortez, 2008.

VIÑAO, A. Espaços, usos e funções: a localização e disposição física da direção escolar na escola graduada. In: Bencostta, M. L. A. (Org.). História da Educação, Arquitetura e Espaço Escolar. São Paulo: Cortez, 2005. 